\title{
Infection in Acromegalic Renal Cysts
}

Yuki Mori ${ }^{1}$, Yuki Otsuka ${ }^{2}$, Yasuhiro Nakano ${ }^{3}$, Hiroyuki SAKAE ${ }^{3}$, Kou Hasegawa ${ }^{1}$, and Fumio Otsuka ${ }^{4}$

${ }^{1}$ Okayama University Graduate School of Medicine Dentistry and Pharmaceutical Sciences

${ }^{2}$ Okayama University Hospital

${ }^{3}$ Affiliation not available

${ }^{4}$ Okayama Daigaku - Shikata Campus

May 18, 2020

\section{Clinical Image}

\section{Infection in Acromegalic Renal Cysts}

Yuki Mori, M.D. ${ }^{1}$, Yuki Otsuka, M.D. ${ }^{1}$, Yasuhiro Nakano, M.D., Hiroyuki Sakae, M.D., Ph.D. ${ }^{1}$, Kou Hasegawa, M.D., Ph.D. ${ }^{1}$ and Fumio Otsuka, M.D., Ph.D. ${ }^{1}$

${ }^{1}$ Department of General Medicine, Okayama University Graduate School of Medicine, Dentistry and Pharmaceutical Sciences, 2-5-1 Shikata-cho, Kita-ku, Okayama 700-8558, Japan

Key words: acromegaly, renal cyst, and urinary tract infection

Disclosure: There is no conflict of interests.

\section{Corresponding author:}

Name: Yuki Otsuka, M.D.

Affiliation: Department of General Medicine, Okayama University Graduate School of Medicine, Dentistry and Pharmaceutical Sciences, Okayama, Japan

Mailing address: 2-5-1 Shikata-cho, Kita-ku, Okayama 700-8558, Japan

Phone number: +81-86-235-7342, Fax number: +81-86-235-7345

E-mail address: otsuka@s.okayama-u.ac.jp

\section{Key Clinical Message}

Renal cysts are detected in one third of acromegaly patients, especially in the uncontrolled cases. Clinicians should pay attention to unexpected infection of enlarged renal cysts in acromegaly patients.

\section{Case}

A 73-year-old female with acromegaly who had been treated with octreotide after transsphenoidal surgery was referred for fever and malaise. Blood tests showed leukocytosis $(14,750 / \mu \mathrm{L})$ with a high serum level of C-reactive protein $(7.29 \mathrm{mg} / \mathrm{dL})$. Serum growth hormone $(\mathrm{GH})$ and insulin-like growth factor (IGF)-I levels were increased to $3.9 \mathrm{ng} / \mathrm{mL}$ and $239 \mathrm{ng} / \mathrm{mL}$, respectively. Enhanced CT revealed enlarged left renal cysts with perinephric panniculitis, indicating infectious cysts (Figure ). Klebsiella pneumoniae was detected from a punctatum of the enlarged cysts and percutaneous drainage with oral levofloxacin was effective. 
Acromegaly is often complicated with cystic formation due to excessive GH. Renal cysts are likely to develop in acromegaly, being detected in one third of patients, particularly in elderly patients and patients with a smoking habit who have high $\mathrm{GH}^{1}$. Simple cysts are mostly asymptomatic; however, intractable urinary infection can occur in developed cysts ${ }^{2}$. Attention must be paid to unexpected infection of acromegalic renal cysts in elderly patients.

\section{Acknowledgments}

None.

\section{Authors' Contribution}

YM and YO: wrote the first draft and managed all the submission process. YN, HS, KH, and FO: contributed to the clinical management of the patients and revised the manuscript.

\section{References}

1. Yamamoto M, Matsumoto R, Fukuoka H, et al. Prevalence of Simple Renal Cysts in Acromegaly. Intern Med. 2016; 55(13):1685-1690.

2. Khan MQ, Ponor IL, Ross AE, Khaliq W. Management of a simple renal cyst in a complex patient. BMJ Case Rep 2013; bcr2013009270.

\section{Figure}

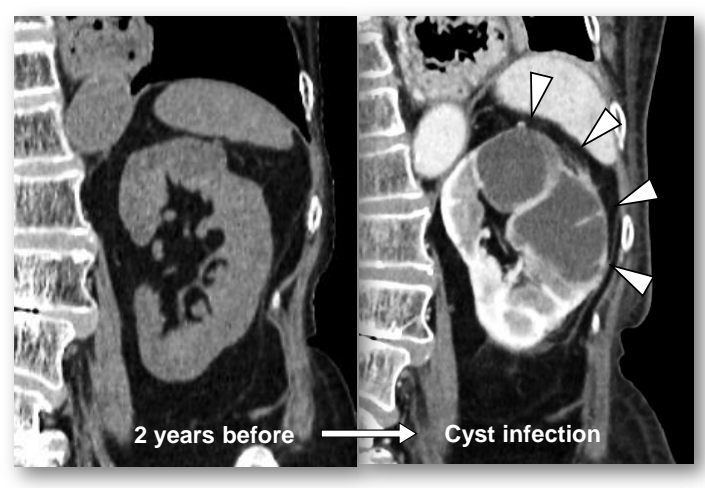

